\title{
ESTAMOS SEMPRE EM GUERRA? ESTUDO COGNITIVO SÓCIO-HISTÓRICO DE UMA METÁFORA DA GRIPE ESPANHOLA E DA COVID-19,
}

\section{ARE WE ALWAYS AT WAR? SOCIO-HISTORICAL COGNITIVE STUDY OF A METAPHOR OF SPANISH AND COVID-19 INFLUENZA}

\section{A. Ariadne Domingues Almeida 2 Universidade Federal da Bahia}

RESUMO: Apresentam-se resultados de um estudo que objetivou refletir sobre a metáfora DOENÇA É GUERRA, no âmbito das pandemias de Gripe Espanhola e COVID-19. Os pressupostos da Semântica Cognitiva Sócio-histórica, vertente da Linguística Cognitiva, alicerçaram teoricamente a pesquisa empreendida que teve natureza qualitativa e foi realizada a partir da abordagem exploratória, descritiva e interpretativa do corpus que, por sua parte, foi constituído por expressões linguísticas coletadas de textos jornalísticos publicados no Jornal Correio da Manhã, em 1918 e em 2020, anos marcados, respectivamente, pelas pandemias de Gripe Espanhola e de COVID-19. Após a finalização do estudo, constatou-se que essa metáfora é estruturada por frames, a exemplo de AÇÃO BÉLICA e ESTRATÉGIA DE GUERRA. Além disso, averiguaram-se diferenças de esquematicidade/especificidade na conceptualização dessas doenças.

PALAVRAS-CHAVE: Metáfora; Domínio; Frame; COVID-19; Gripe Espanhola.

1 Para Lorenna Oliveira e Dalva Barreto.

2 Endereço eletrônico: ada.domingues@gmail.com 
Abstract: The results of a study that aimed to reflect on the metaphor DISEASE IS WAR, in the context of the Spanish Flu and COVID-19 pandemics. The assumptions of Socio-historical Cognitive Semantics, a branch of Cognitive Linguistics, were the theoretical basis of the research undertaken. The research was qualitative and was performed from the exploratory, descriptive, and interpretive approach of the corpus that, in turn, was composed of linguistic expressions collected from journalistic texts published in the Correio da Manhã newspaper in 1918 and 2020, years marked, respectively, by the Spanish Flu and the COVID-19 pandemics. After the study was finished, it was found that this metaphor is structured by frames, such as WARLIKE ACTION and WAR STRATEGY. Furthermore, differences in schematicity/specificity in the conceptualization of these diseases were ascertained.

Keywords: Metaphor; Domain; Frame; COVID-19; Spanish flu.

\section{PARA INICIAR A DISCUSSÃO}

Quando a COVID-19 despontou na China, a imprensa começou a noticiála e, com sua chegada ao Brasil, o trabalho dos veículos de comunicação do país foram intensificados. Por conseguinte, reportagens, artigos de opinião, entre outros gêneros do domínio discursivo jornalístico, passaram a refletir a propósito dessa desconhecida doença, a fim de oferecer aos seus leitores informações sobre o problema, com a finalidade de compreendê-lo melhor. Com isso, jornalistas produziram, por exemplo, um paralelo entre a COVID-19 e a Gripe Espanhola, em seus textos, a exemplo dos que se intitulam: 8 semelhanças entre a covid-19 e a gripe espanhola3; Como há 100 anos Brasil registra mais de 35 mil mortes por covid-19 e ultrapassa óbitos da gripe espanhola no país ${ }^{4}$ Covid-19 tem potencial para ser tão séria quanto gripe espanhola, diz Fauci5.

Além de proceder à comparação entre essas duas enfermidades e de estabelecer convergências e divergências entre esses quadros pandêmicos, a imprensa passou a discutir o uso da metáfora da guerra no âmbito da pandemia de SARS-CoV-2 - o novo coronavírus. Com isso, textos foram publicados,

\footnotetext{
${ }^{3}$ Disponível em: https://querobolsa.com.br/revista/8-semelhancas-entre-a-covid-19-e-a-gripeespanhola Acesso em: 03 ago. 2020.

${ }^{4}$ Disponível em: https://noticias.uol.com.br/reportagens-especiais/ao-superar-35-mil-mortescovid-19-se-torna-mais-letal-que-gripe-espanhola-no-brasil/ Acesso em: 03 ago. 2020.

${ }^{5}$ Disponível em: https://noticias.uol.com.br/internacional/ultimas-noticias/2020/07/14/covid19-tem-potencial-para-ser-tao-seria-quanto-gripe-espanhola-diz-fauci.htm Acesso em: 03 ago. 2020.
} 
questionando o papel dessa metáfora na construção da realidade, a exemplo de: Metáfora da guerra não faz bem à saúde pública ou à democracia ${ }^{6}$ e Contra o novo coronavírus, lógica da guerra mais compromete do que salva vidas ${ }^{7}$. Esses títulos deixam patente que essa metáfora não foi bem vista por formadores de opinião, embora seja amplamente requerida por vários agentes sociais tanto aqui quanto no exterior, para falar, escrever, enfim, para pensar sobre a nova pandemia e agir diante desse problema sanitário.

Em face das reflexões postas em textos jornalísticos que circularam no Brasil entre janeiro e agosto de 2020, considerou-se necessário verificar se a Gripe Espanhola também foi compreendida em termos de guerra, bem como se julgou pertinente observar como essa metáfora se manifestou linguisticamente em textos do mencionado domínio discursivo nesses dois períodos históricos. O estudo empreendido então objetivou compreender como ocorreu a conceptualização metafórica dessas doenças pandêmicas em termos de GUERRA, a partir, respectivamente, de textos do referido domínio discursivo jornalístico publicados nos séculos XX e XXI, com a finalidade de identificar manutenções, mudanças e variações no âmbito dos frames acionados nessa conceptualização metafórica e de averiguar se houve ou não diferenças no modo de escrever sobre essas enfermidades.

Os postulados da semântica em perspectiva cognitiva sócio-histórica constituíram as bases teóricas do estudo aqui apresentado e o corpus utilizado para sua realização foi constituído por expressões linguísticas coletadas em textos publicados no Jornal da Manhã, em 1918 e 2020, anos em que, respectivamente, despontaram no Brasil a Gripe Espanhola e a COVID-19. A seguir, tecem-se considerações acerca do citado alicerce teórico.

${ }^{6}$ Disponível em: https://www1.folha.uol.com.br/colunas/lucia-guimaraes/2020/04/metaforada-guerra-nao-faz-bem-a-saude-publica-ou-a-democracia.shtml?origin=uol Acesso em: 12 ago. 2020.

7 Disponível em: https://oglobo.globo.com/brasil/artigo-contra-novo-coronavirus-logica-daguerra-mais-compromete-do-que-salva-vidas-1-24398475 Acesso em: 12 ago. 2020. 


\section{O APORTE TEÓRICO: A SEMÂNTICA EM PERSPECTIVA COGNITIVA-SÓCIO-HISTÓRICA}

Nos anos 1990, estudiosos, a exemplo de Geeraerts (1997), entenderam que as pesquisas sobre a significação na flecha do tempo não poderiam prescindir dos fundamentos da segunda onda dos estudos cognitivistas. Com isto, colocaramse a pensar a respeito das inter-relações entre as dimensões histórica e cognitiva na geração do significado. Seus estudos fizeram emergir a Semântica Cognitiva Diacrônica também chamada Semântica Histórica Cognitiva e ainda Semântica Histórico-Diacrônica ${ }^{8}$, entre outras possibilidades de nomeação.

Em face dessa variação da nomenclatura, pesquisadores, como Almeida (2020a), visando à precisão da terminologia, têm usado o termo Semântica Cognitiva Sócio-histórica (SCSH), para nomear essa recente abordagem do significado. Esse uso procura destacar a inter-relação entre as dimensões cognitiva, social e histórica. Esse destaque é necessário, primeiramente, para delimitar o alcance dos estudos da área, isto porque pesquisas diacrônicas atentam para a temporalidade sem necessariamente terem em conta a historicidade, como demonstram Mattos e Silva (2008) e Sousa (2006); também, porque a cognição humana é situada, de modo que não é cabível desconsiderar essa inter-relação no complexo da linguagem, isto é, no tecido junto das dimensões da vida hominal, entrelaçadas na emergência textual do discurso, quando, nas interações cotidianas, ocorre a construção dos significados, responsável por criar os mundos e determinar as ações da espécie humana.

Para proceder ao estudo do significado, a SCSH adota teorias, como: Teoria do Protótipo, da Metáfora e Metonímia Conceptuais, dos Modelos

\footnotetext{
${ }^{8}$ A nomenclatura dessa abordagem semântica acha-se em variação. Assim, Fernández Jaén (2007; 2016) emprega os termos Semântica Histórica, Semântica Histórica Cognitiva, Semântica Cognitiva Diacrônica e Semântica Diacrônica. Já Paz Afonso (2014) usa Semântica Diacrônica Cognitiva, Semântica Histórica Cognitiva, Semântica Diacrônica e Semântica Histórico-Diacrônica.
} 
Cognitivos Idealizados, da Semântica de Frames e, com base em seus pressupostos, busca responder às suas próprias questões de pesquisa, a exemplo de: Como ocorre a conceptualização humana no devir do tempo? Como atuam as dimensões histórica, social, entre outras, na manutenção, mudança e variação do significado? Como as figuras do pensamento e da ação atuam nessa manutenção, mudança e variação semântica? Como são possíveis a mudança e a variação na linguagem, diante da manutenção de padrões de organização semântica?

Por ser uma ilha teórica do arquipélago da Linguística Cognitiva, a SCSH, seguindo postulados de Lakoff (2013 [2006]), estuda o modo como o ser humano conceptualiza, como pensa, fala e aqui acrescenta-se como escreve sobre a vida em todas as suas dimensões. A conceptualização é, portanto, uma perspectivação dos conceptualizadores relativamente a algo, seja entidade, situação, estado, ação (SILVA; BATORÉO, 2010). Conceptualizar é significar e o significado é flexível, dinâmico, perspectivista, elaborado no uso da linguagem feito pelo ser humano, ser dotado de uma mente corporificada, de uma cognição situada, como já posto.

O significado, sendo flexível e dinâmico, muda e varia, e isto decorre do fato de ser o resultado de uma perspectivação conceptual. O significado é então, como destaca Silva (2008), o meio de que os seres humanos dispõem para a construção dos seus mundos que são sempre elaborados a partir de uma perspectiva ou de perspectivas variáveis. Logo, as expressões linguísticas carregam perspectivas, isto porque falar e escrever requerem sempre que o conceptualizador faça uma opção em uma determinada situação.

As metáforas, por sua parte, são uma operação de conceptualização e Lakoff e Johnson, na obra seminal de 1980, postulam que "a essência da metáfora é compreender e experienciar uma coisa em termos de outra" (LAKOFF; JOHNSON, 2002 [1980], p. 47-48). E em seu livro de 1996, Lakoff explicita que a metáfora é um componente do sistema conceptual, uma correspondência entre dois conceitos que transcende domínios conceptuais e que possibilita que formas 
de raciocínio e vocábulos próprios de um domínio sejam usados em outro (LAKOFF, 2016 [1996]).

Além disso, é extremamente comum que metáforas se fixem nos sistemas conceptuais e ajudem o ser humano a esculpir os modelos de pensamento cotidiano. Quase sempre, são usadas sem qualquer esforço, de modo aparentemente inconsciente, embora desempenhem um papel fundamental na formação das distintas visões de mundo dos variados grupos sociais (LAKOFF, 2016 [1996]). Realizam-se em um conjunto aberto e variável de expressões diferentes, chamadas expressões metafóricas (LAKOFF; JOHNSON, 2002 [1980]).

A metáfora constitui um esquema ou padrão conceptual sob a forma XÉ Y, ou, como é possível concluir pela leitura de Barcelona (2003), X É (PARCIALMENTE) Y ou DOMÍNIO-ALVO É (PARCIALMENTE) DOMÍNIO FONTE, como posto por Almeida e Santos (2020). Então, a partir de um domíniofonte, mais concreto, bem conhecido, mais próximo da experiência física do ser humano, torna-se possível entender, por meio de projeções, um domínio-alvo, mais abstrato, pouco conhecido, mais próximo das suas experiências emocionais e psíquicas. O domínio-fonte é a origem da estrutura conceptual importada para o alvo e as projeções, como antes destacado, não são totais, mas parciais, logo, os mapeamentos projetam parte da estrutura do domínio-fonte para o alvo.

Sobre os domínios estáveis de conhecimento, o uso do rótulo frame ${ }^{9}$, para nomeá-los, tem se generalizado e seu emprego tem sido uma tendência nos estudos cognitivistas, como chamam a atenção Albergaria e Miranda (2011). Kövecses (2017), por sua parte, destaca que não é possível identificar diferenças entre domínios e frames $^{10}$, se domínio for definido como uma área coerente de

\footnotetext{
${ }^{9}$ Fillmore (2009 [1982]) define frame como um sistema de conceitos relacionados, de tal modo que, para entender um deles, é preciso entender toda a estrutura em que se enquadram.

${ }^{10}$ Croft e Cruse (2008) afirmam que o termo domínio é usado por Langacker (1987) para fazer referência à base e observam que Lakoff (1987) também usa esse mesmo termo, bem como assinalam a equivalência entre base/domínio e frame, como postulado por Fillmore (1982). Assim, Croft e Cruse destacam a equivalência terminológica assinalada por Kövecses (2017).
} 
conceptualização em relação à qual unidades semânticas podem ser caracterizadas, conforme proposto por Langacker (1987). Todavia, o mesmo Kövecses (2017) pondera que essas duas estruturas conceptuais podem ser diferenciadas em termos de esquematicidade. Assim, enquanto os domínios são mais esquemáticos, os frames possuem menor esquematicidade, envolvem mais informações conceptualmente específicas.

Para demonstrar a diferença entre essas estruturas conceptuais, o referido autor traz, como exemplo, o domínio CORPO, constituído por frames, como PERCEPÇÃO, INGESTÃO e EXERCÍCIO. Esses frames são responsáveis por expressões linguísticas metafóricas, como: eu vejo o que você quer dizer (PERCEPÇÃO), digerir uma ideia (INGESTÃO) e um exercício mental (EXERCÍCIO). Juntos formam o que se chama de metáfora de nível genérico: MENTE É CORPO. O mesmo pesquisador observa ainda que, em geral, os frames que elaboram um domínio consistem em papéis e relações entre papéis que podem ser preenchidos por valores específicos (KÖVECSES, 2017).

As significações metafóricas são tratadas como relações semânticas que ocorrem entre frames de um domínio e as metáforas, como mecanismos de conceptualização, possibilitam que frames, ao serem acionados ${ }^{11}$, atuem na construção das diferentes visões de mundo que, idealizadas, podem ser até opostas entre si. Assim, como expressa Lakoff (2013 [2006]; 2016 [1996]), os frames são estruturas mentais que permitem os humanos compreenderem e criarem o que é chamado de realidade. São usados, em boa parte, de modo inconsciente, automático e facilitam as interações humanas com o mundo, estruturando suas ideias e conceitos, dando forma à sua maneira de raciocinar, incidindo em sua percepção, determinando seu comportamento e seu modo de agir.

${ }_{11}$ Os elementos partícipes dos mapeamentos, em geral, são dados na forma de frames que, sendo menos esquemáticos, elaboram os elementos selecionados dos domínios. Assim sendo, os frames de origem oferecem mais informações específicas do que os domínios (KÖVECSES, 2017). 
Enfim, conforme Lakoff (2013 [2006]), os frames definem temas, caracterizam problemas, determinam causas, repartem culpas, reduzem soluções e, ao definirem temas, inibem preocupações relevantes que estão fora desses frames, ocultam outros temas e causas importantes. A evocação de um frame, portanto, requer sempre que se assuma um ponto de vista específico sobre algo ou sobre alguém (SALOMÃO; TORRENT; SAMPAIO, 2013), resultando na imposição de uma perspectiva. Portanto, a ativação de um frame inibe outros possíveis frames. Por conseguinte, as ações que o ser humano realiza só fazem sentido dentro dos enquadramentos que definem um tema.

As possibilidades alternativas de enquadres proporcionam as formas de variação do significado. Assim sendo, frames implicam operações de perspectivação conceptual, dentre essas, acham-se a proeminência ou saliência que é (des)focalização de elementos de uma situação, compreendendo a assimetria figura/fundo e perfil/base ${ }^{12}$. Outra operação de perspectivação conceptual diz respeito ao fato de algo poder ser conceptualizado com distintas escalas de esquematicidade/especificidade (SILVA, 2019), determinantes do grau de detalhe e de precisão com que algo é caracterizado, além das metáforas e de outras operações, conforme observado por Croft e Cruse (2008).

Feita a exposição do norte teórico que viabilizou o estudo do corpus, a seguir, apresenta-se a base metodológica que tornou possível tecer, junto aos pressupostos teóricos, os resultados aduzidos neste artigo.

${ }_{12}$ A assimetria perfil/base encontra-se em todas as expressões linguísticas, visto que as expressões impõem um perfil em uma base. O perfil faz referência ao conceito simbolizado por uma palavra, enquanto a base refere-se ao conhecimento ou estrutura conceptual presumida por parte do conceito perfilado. Já o domínio é empregado, da mesma maneira, para fazer referência à base (CROFT; CRUSE, 2008), como aqui antes já assinalado. 


\section{O PERCURSO METODOLÓGICO}

O estudo teve natureza qualitativa, com a abordagem exploratória, descritiva, interpretativa do corpus, formado por textos jornalísticos. Para constituí-lo, seguiu-se a proposta de Almeida (2020b), desenvolvida com base na Teoria dos Fractais, que possibilita pensar a constituição de corpus para a realização de estudos do significado no passado e, também, no presente. Assim, ao formá-lo, considerou-se que a parte está no todo e o todo está na parte, bem como se ponderou que o padrão de organização semântica se repetirá infinitamente, enquanto um conceito existir. Daí, por exemplo, a metáfora AMOR É ORGANISMO VIVO se encontrar documentada em pequenas e grandes parcelas de textos dos séculos XIX e XX, conforme demonstrou Santana (2019).

Com base na compreensão do corpus e também da linguagem como um fractal, coletou-se o material textual, usando a Técnica da Saturação, uma ferramenta conceitual usada em pesquisas qualitativas, que funciona como um critério para delimitar a interrupção da coleta de dados e a definição do tamanho da amostra. No âmbito do estudo realizado, a saturação ocorreu, quando a coleta chegou a um ponto em que não foram localizadas novidades e os dados se repetiram, apresentando redundâncias. Quando foi verificado o ponto de saturação, realizou-se, ainda, a leitura de mais um terço do número de textos que geraram a amostra, para que o fechamento amostral fosse atingido com segurança.

No trabalho empreendido, essa técnica foi aplicada ao jornal Correio da Manhã. Trata-se de um periódico brasileiro, publicado, em sua primeira fase, no Rio de Janeiro, de 15 de junho de 1901 a 8 de julho de 1974. Esse jornal conheceu uma interrupção de suas atividades por quatro décadas, mas essas foram retomadas em 201913. Para acessar os textos publicados nesse jornal no século XX,

13 Disponível: https://www.jornalcorreiodamanha.com.br/editorial/2260-cada-vez-maiscorreio-da-manha e https://www.jornalcorreiodamanha.com.br/rio-de-janeiro/505-correioda-manha-ganha-premio-sao-sebastiao Acesso em: 02 ago. 2020. 
utilizou-se a Hemeroteca ${ }^{14}$, e, para os publicados agora, usou-se o próprio site do jornal. Para proceder à seleção do material textual que foi estudado, empregouse o motor de busca de ambos, a fim de procurar, respectivamente, nos textos de 1918 e de 2021, por grippe hespanhola/influenza hespanhola e covid-19.

Depois de identificados os textos em que esses itens do léxico se registravam, realizou-se a leitura integral de cada texto. Posteriormente, foi delimitada a amostra, usando a técnica em pauta, para identificar quando ocorreu no referido jornal a saturação do domínio GUERRA, alcançado pela linguagem dos textos; concomitante ao levantamento das expressões metafóricas, foi feita a identificação dos frames desse domínio.

Durante a realização da leitura, constatou-se que o item léxico pandemia não se registrou no material textual coletado no século $X X$, de sorte que apenas epidemia foi localizado no referido século. Além disso, verificou-se que esse último item léxico foi apenas utilizado uma única vez no corpus do século XXI, de modo que agora predomina o uso de pandemia. Assim, resolveu-se tomar o item léxico doença na notação do domínio-alvo da metáfora, tendo em vista que DOENÇA é um domínio mais esquemático e, por isso, compreenderia também os frames PANDEMIA e EPIDEMIA, em cada período, separadamente.

Com base na discussão feita por Croft e Cruse (2008) sobre os domínios, usaram-se, para identificação dos frames, os itens léxicos e as construções linguísticas constituintes do corpus. Este procedimento foi realizado, conforme os textos iam sendo lidos. Selecionadas as passagens dos textos em que os usos linguísticos documentavam os frames do domínio-fonte GUERRA, foi feita, a partir desses frames, a organização desse material textual, ordenando-o por século, lado a lado, em quadros e, quando não foram localizados, no corpus, exemplos da linguagem que instanciam um dado frame, informou-se essa

14 A Hemeroteca Digital Brasileira é um portal de periódicos publicados no Brasil em diferentes períodos da história do país. Disponível em: Coleção Digital de Jornais e Revistas da Biblioteca Nacional (bn.br) Acesso em 02 ago. 2020. 
ausência nesses quadros. Os exemplos foram numerados em ordem crescente e em algarismo arábico. Ademais, usou-se itálico para marcar as expressões indicativas dos frames e do domínio GUERRA e inseriram-se os links dos textos e as respectivas datas de acesso em notas de rodapé. A ortografia e a acentuação foram mantidas, como postas no jornal, nos dois períodos, respectivamente.

Com isso, o estudo do corpus foi sendo realizado, para apontar manutenções, variações e mudanças nos frames acionados, na linguagem dessas pandemias. A seguir, serão expostos os resultados do estudo.

\section{O ESTUDO DA METÁFORA DOENÇA É GUERRA}

O acionamento do domínio-fonte GUERRA para a compreensão das doenças implica frames, como EXÉRCITO, COMANDANTE, LUTA, BATALHA, CAMPO DE BATALHA, DERROTA DO INIMIGO, SOLDADO etc., que delimitam papeis semânticos. No processamento metafórico, então, projeções de elementos de frames desse domínio para o da DOENÇA possibilitam entender a perda da saúde em termos de um conflito armado e juntos esses frames formam a metáfora convencional e mais geral DOENÇA É GUERRA que, por sua vez, torna possível metáforas mais específicas, como EPIDEMIA/PANDEMIA É GUERRA. Assim, frames do domínio-fonte GUERRA participam da conceptualização da Gripe Espanhola e da COVID-19, de modo a viabilizar o uso da linguagem da guerra para falar e também escrever, além de pensar e agir, sobre os problemas de saúde, em geral, e sobre as epidemias e as pandemias, em particular.

O quadro 1 apresenta expressões linguísticas metafóricas resultantes do acionamento do frame AÇÃO BÉLICA na conceptualização dessas pandemias: 
Quadro 1 - Frame AÇÕES BÉLICAS e expressões metafóricas

\begin{tabular}{|c|c|}
\hline \multicolumn{2}{|l|}{ FRAME: AÇÃO BÉLICA } \\
\hline SÉCULO XX: GRIPPE HESPANHOLA & SÉCULO XXI: COVID-19 \\
\hline $\begin{array}{l}\text { (01) "Para combater o mal, caso ele chegue até } \\
\text { nós, diz o dr. Carlos Chagas }[\ldots]^{15 "}\end{array}$ & $\begin{array}{l}\text { (03) “[...] O soro de pessoas curadas da doença } \\
\text { - que contém os anticorpos para combatê-la - } \\
{[\ldots]^{17 "}}\end{array}$ \\
\hline $\begin{array}{l}\text { (02) "[...] Reuniram-se hontem, nesta capital, } \\
\text { os médicos da hygiene, afim de tratarem da } \\
\text { epidemia de grippe. Resolveram combatel-a } \\
\text { energeticamente }[. . .]^{16 "}\end{array}$ & $\begin{array}{l}\text { (04) “[...] os países mais ricos do mundo } \\
\text { concentram seus esforços domésticos na luta } \\
\text { contra o novo coronavírus (Covid-19) }[\ldots]^{18 "}\end{array}$ \\
\hline
\end{tabular}

O acionamento desse frame garante o tratamento dessas pandemias como um conjunto de atos empreendidos em uma campanha militar com a finalidade de submeter um inimigo à derrota. Nesse sentido, em (04), luta ${ }^{19}$ apresenta maior grau de esquematicidade e resulta de uma conceptualização mais generalizante, já em (01), (02) e (03), combate ${ }^{20}$ apresenta menor esquematicidade e requer, portanto, maior especificidade, isto, ao se considerar que lutas compreendem combates, os quais, se comparados às batalhas, possuem menor amplitude,

\footnotetext{
${ }^{15}$ Disponível em:
}

http://memoria.bn.br/DocReader/DocReader.aspx?bib=089842_02\&pesq=grippe\%20hespanh ola\&pasta=ano\%20191\&pagfis=36796 Acesso em: 18 ago. 2020 .

${ }^{16}$ Disponível em:

http://memoria.bn.br/DocReader/DocReader.aspx?bib=089842_02\&pesq=grippe\%20hespanh ola\&pasta=ano\%20191\&pagfis=36878 Acesso em: 18 ago. 2020.

${ }^{17}$ Disponível em: https://www.jornalcorreiodamanha.com.br/saude/2331-vacas-e-cavalos-setornam-fabricas-de-anticorpos-contra-a-covid-19 Acesso em: 18 ago. 2020.

18 Disponível em: https://www.jornalcorreiodamanha.com.br/internacional/1661-covid-19tratamentos-mas-a-que-preco Acesso em: 18 ago. 2020.

${ }^{19}$ Entendeu-se que luta apresenta maior grau de esquematicidade e menor especificidade, com base nas seguintes definições dicionarísticas: Luta: “[...] 2 qualquer contenda com ou sem armas; conflito, guerra [...]" (HOUAISS, 2020). “Luta: [...] 2. Conflito armado, guerra (luta civil) (AULETE, 2020). Essas definições são generalizantes, com menos teor de informação. Como visto, luta é definida, no Houaiss, a partir do hiperônimo contenda, que, por sua parte, pode ser enquadrado de distintas maneiras e o Aulete define luta como conflito armado e pelo sinônimo de guerra. Assim, essas definições autorizam entender luta como um item léxico que pode apresentar um conteúdo informativo mais generalizante.

${ }^{20}$ Compreendeu-se que combate é um item léxico mais específico em relação à luta, a partir das seguintes definições: Combate: "1. Mil. luta entre forças militares, de extensão menor que a batalha e travada em espaço restrito entre grupos pouco numerosos" (HOUAISS, 2020). Combate: "[...] Mil. Ação bélica de menor amplitude que a batalha, travada em área restrita" (AULETE, 2020). O Houaiss aponta para o fato de combate ser hipônimo do hiperônimo luta e o Aulete o define como uma ação bélica de menor alcance, logo o entende também de forma mais específica do que luta. 
ocorrem em um espaço restrito e com reduzido contingente de militares. Assim sendo, ainda que compartilhem a mesma base conceptual, luta e combate perfilam diferentes aspectos, tratando-se, por conseguinte, de distintos recortes dessa base conceptual mais ampla. Isto posto, conclui-se que, no corpus, a situação foi perspectivada de uma forma mais geral, mais esquemática, apenas, no século XXI, em (04), embora nesse mesmo período, a pandemia de COVID-19 tenha sido também descrita, em (03), de uma maneira mais específica e menos esquemática, como aconteceu, no século XX, com a Gripe Espanhola.

Assim como AÇÕES BÉLICAS, o frame CAMPO DE BATALHA é parte do domínio GUERRA, por conseguinte, pode ser acionado para a compreensão metafórica dessas pandemias. Contudo, no corpus, esse acionamento não foi identificado no século XX. Daí apenas o registro da expressão linguística linha de frente que perfila, no século XXI, em (05), a parte do local onde os combatentes se encontram mais próximos dos inimigos, onde o conflito bélico, de fato, acontece. Esse acionamento torna possível, então, a compreensão dos agentes da saúde como guerreiros postos por um estrategista de guerra no setor mais avançado das tropas envolvidas no conflito bélico contra o inimigo vírus:

Quadro 2 - Frame CAMPO DE BATALHA e expressões metafóricas

\begin{tabular}{|c|c|}
\hline \multicolumn{2}{|l|}{ FRAME: CAMPO DE BATALHA } \\
\hline SÉCULO XX: GRIPPE HESPANHOLA & SÉCULO XXI: COVID-19 \\
\hline $\begin{array}{l}\text { No corpus do século XX, não foram } \\
\text { identificados exemplos do acionamento desse } \\
\text { frame. }\end{array}$ & $\begin{array}{l}\text { (05) "Os voluntários serão cerca de } 2.000 \\
\text { profissionais de saúde que atuam na linha de } \\
\text { frente no combate à Covid-19 e, portanto, têm } \\
\text { mais risco de contrair o vírus }{ }^{21 "}\end{array}$ \\
\hline
\end{tabular}

Fonte: própria autora

Em (05), como antes informado, é perfilado um local de atuação do guerreiro no combate. A seleção desse perfil, ao mesmo tempo em que demonstra o foco de atenção da conceptualização realizada, impossibilita ativar outras estruturas conceptuais evocadas por outros elementos do léxico, como flanco e retaguarda, que perfilam entidades conceptuais desse mesmo frame, tão

21 Disponível em: https://www.jornalcorreiodamanha.com.br/saude/2687-segundo-estudovacina-de-oxford-contra-covid-19-e-segura-e-da-resposta-imune Acesso em: 18 ago. 2020. 
esquemáticos quanto linha de frente, mas não identificados nesse corpus, isto porque as projeções metafóricas são sempre parciais.

Vale observar, nesse sentido, que o estudo do material textual coletado permitiu constatar que, na conceptualização identificada no corpus do século passado, a seleção da atenção não se deu na direção de onde ocorre propriamente o conflito belicoso, mas se dirigiu, por exemplo, para o provável local de desembarque do inimigo vírus, como demonstra a seguinte expressão linguística: "[...] evitar a invasão da "influenza hespanhola" no nosso porto [...] $]^{22 " . ~ E m ~ r a z a ̃ o ~ d e s t a ~}$ diferença, esse exemplo não foi incluído no quadro 2 que apresenta exclusivamente o frame CAMPO DE BATALHA, como já visto.

Em face do exposto, presume-se que o foco de atenção dos escreventes conceptualizadores, diante desses eventos pandêmicos, é distinto e isto gera enquadramentos diversos, com o acionamento de diferentes frames, mesmo tendo ocorrido, nos exemplos coletados nos textos das duas centúrias, o perfilamento de um espaço.

Como uma base é constituída por distintos perfis conceptuais interrelacionados e como isto se manifesta nos mais variados textos, os exemplos arrolados nos quadros 1 e 2 também deixam saber que as doenças, entendidas em termos de guerra, além de requererem ações belicosas experienciadas em uma dada área, exigem a compreensão da existência de adversários, por conseguinte, é acessado, para a conceptualização dessas pandemias, o frame MILITAR que, por sua parte, constitui-se de outros frames, dentre esses, no corpus, registram-se expressões linguísticas que instanciam os seguintes: GENERAL, SOLDADO, SOLDADO MORTO e INIMIGO, conforme respectivamente expresso nos quadros 3, 4, 5 e 6. A seguir, apresentam-se exemplos do acionamento do frame GENERAL: 
Quadro 3 - Frame GENERAL e expressões metafóricas

\begin{tabular}{|l|l|}
\hline \multicolumn{2}{|l|}{ FRAME: GENERAL } \\
\hline \multicolumn{1}{|c|}{ SÉCULO XX: GRIPPE HESPANHOLA } & \multicolumn{1}{|c|}{ SÉCULO XXI: COVID-19 } \\
\hline (06) “[...] o dr. Carlos Seidl, director da Saude & (07) "Cientistas [...] estão usando animais de \\
Publica, deu conta [...] das providencias e medidas & $\begin{array}{l}\text { grande porte para produção de soro com } \\
\text { tomadas para evitar a invasão da "influenza } \\
\text { anticorpos contra o novo coronavírus [...] }]^{24 "} \\
\text { hespanhola" no nosso porto [...] }{ }^{23 "}\end{array}$ \\
\hline
\end{tabular}

Fonte: própria autora

O acionamento dos frames GENERAL - exposto no quadro 3 - e ainda SOLDADO - expresso no quadro 4 - viabiliza compreender os agentes da Saúde em termos de tipos de militares atuantes nas guerras. Assim sendo, enquanto as pessoas que a administram e os seus pesquisadores são vistos como estrategistas que traçam os modos para ganhar as batalhas, os combates, enfim, a guerra, outros agentes da área são entendidos como os que buscam, sob as orientações desses comandantes, impelir derrota ao oponente.

Então, no corpus do século XX, em (06), o general é o director da Saúde Pública, dr. Carlos Seidl, enquanto os médicos da hygiene são, em (08), os soldados que lutam contra o adversário vírus a ser derrotado. Já, na pandemia de agora, em (07), os cientistas são conceptualizados como generais que criam as formas para derrotar o inimigo e os voluntários profissionais de saúde são, em (09), os soldados que vão para linha de frente contra esse poderoso rival militar.

Além disso, no tocante aos estrategistas, nos Novecentos, a atenção foi direcionada à administração/política, focalizando, em (06), o diretor da saúde, enquanto agora, em (07), a focalização se deu em face da ciência, por conseguinte, o foco foi posto nos cientistas. Já no que concerne aos soldados, a atenção, nos dois períodos, foi toda lançada para a saúde, de tal sorte que exclusivamente seus trabalhadores foram focalizados, como mostram os exemplos (08) e (09):

${ }^{23}$ Disponível em:

http://memoria.bn.br/DocReader/DocReader.aspx?bib=089842_02\&Pesq=grippe\%20hespanh ola\&pagfis=36840 Acesso em: 19 ago. 2020.

${ }^{24}$ Disponível em: https://www.jornalcorreiodamanha.com.br/saude/2331-vacas-e-cavalos-setornam-fabricas-de-anticorpos-contra-a-covid-19 Acesso em: 19 ago. 2020. 
Quadro 4 - Frame SOLDADO e expressões metafóricas

\begin{tabular}{|l|l|}
\hline \multicolumn{2}{|l|}{ FRAME: SOLDADO } \\
\hline \multicolumn{1}{|c|}{ SÉCULO XX: GRIPPE HESPANHOLA } & \multicolumn{1}{|c|}{ SÉCULO XXI: COVID-19 } \\
\hline $\begin{array}{l}\text { (08) “[...] Reuniram-se hontem, nesta capital, os } \\
\text { médicos da hygiene, afim de tratarem da } \\
\text { epidemia de grippe }[. . .]]^{25 "}\end{array}$ & $\begin{array}{l}\text { (09) “Os voluntários serão cerca de } 2.000 \\
\text { profissionais de saúde que atuam na linha de } \\
\text { frente no combate à Covid-19 e, portanto, } \\
\text { têm mais risco de contrair o vírus"26" }\end{array}$ \\
\hline
\end{tabular}

Fonte: própria autora

Se comparados os quadros 3 e 4, constata-se que, nos exemplos coletados do corpus, em (06), há uma maior especificidade, de modo que Carlos Seidl perfila o próprio dirigente das ações para restaurar a saúde pública, o que não ocorre, em (07), em relação aos cientistas, apresentados como um conjunto. Por conseguinte, (06) e (07) diferem-se em termos de esquematicidade/especificidade e ainda em termos de uno/múltiplo, já que, no século $X X$, é informado o nome próprio da pessoa responsável por dirigir a saúde, enquanto no XXI é usado um nome comum que indica genericamente uma classe profissional.

Em (08) e (09), nos exemplos dos dois séculos, a conceptualização foi realizada com maior grau de esquematicidade, de modo que não foram dados os nomes dos soldados/médicos da hygiene, nem dos soldados da linha de frente/ voluntários-profissionais da saúde, tendo sido citados apenas os termos referentes à classe dos trabalhadores da área, sem especificá-los, portanto sem maior conteúdo informativo. Contudo, ainda que sejam conceptualizações generalizantes, há maior especificidade, em (08), já que médico da hygiene é um hipônimo de profissionais da saúde, hiperônimo, visto em (09). Embora ocorra essa diferença de grau, ao se compararem os exemplos, constata-se que (08), no geral, oferece uma conceptualização mais esquemática, em relação a outras, por exemplo de (06), em que o antropônimo do director da saúde é indicado no texto.

http://memoria.bn.br/DocReader/DocReader.aspx?bib=089842_02\&pesq=grippe\%20hespanh ola\&pasta=ano\%20191\&pagfis=36878 Acesso em: 19 ago. 2020.

26 Disponível em: https://www.jornalcorreiodamanha.com.br/saude/2687-segundo-estudovacina-de-oxford-contra-covid-19-e-segura-e-da-resposta-imune Acesso em: 19 ago. 2020. 
A maior esquematicidade, identificada em (07), (08) e (09), provavelmente, ocorre por economia cognitiva, uma vez que seriam diversos nomes a serem arrolados, demandando esforço, além de implicações de ordem socioeconômicas.

O acionamento do frame SOLDADO MORTO torna possível compreender as mortes resultantes da Gripe Espanhola e da COVID-19 como baixas que ocorrem nos campos de batalha, decorrentes das mortes de militares atuantes no conflito. No corpus, expressões linguísticas usadas nos dois períodos instanciam a metáfora da guerra e os itens léxicos vitimado e vítima perfilam, em particular, as pessoas que, durante a guerra, perdem a vida. No exemplo coletado no século XX, em (10), os membros da missão naval e da missão medica são os vitimados pela Gripe Espanhola, já no século XXI, em (11), a vítima não tem classe profissional determinada nem nome definido, de modo que apenas é apresentada como o número indicativo do primeiro ser humano a falecer por COVID-19. Assim, se comparados esses exemplos, no século passado, houve maior grau de especificidade, diferentemente do que acontece no século XXI, em que há maior esquematicidade:

Quadro 5 - Frame SOLDADO MORTO e expressões metafóricas

\begin{tabular}{|c|c|}
\hline \multicolumn{2}{|l|}{ FRAME: SOLDADO MORTO } \\
\hline SÉCULO XX: GRIPPE HESPANHOLA & SÉCULO XXI: COVID-19 \\
\hline $\begin{array}{l}\text { (10) "Os membros da missão naval e da missão } \\
\text { medica, que foram victimados pela Influenza } \\
\text { hespanhola }[. . .]^{27 "}\end{array}$ & $\begin{array}{l}\text { (11) "O prefeito da cidade }[. . .] \text { foi quem } \\
\text { anunciou a primeira vítima da pandemia que } \\
\text { atingiu o Brasil }[\ldots]^{28 "}\end{array}$ \\
\hline
\end{tabular}

Fonte: própria autora

A personificação do vírus proporcionada pelo acionamento do frame MILITAR na conceptualização metafórica das pandemias em termos de guerra torna possível entender o vírus como o adversário a ser derrotado:

http://memoria.bn.br/DocReader/DocReader.aspx?bib=089842_02\&pesq=grippe\%20hespanh ola\&pasta=ano\%20191\&pagfis=36830 Acesso em: 16 ago. 2020 .

${ }^{28}$ Disponível em: https://www.jornalcorreiodamanha.com.br/brasil/1530-porto-alegre-temprimeira-vitima-fatal-de-covid-19 Acesso em: 16 ago. 2020. 
Quadro 6 - Frame INIMIGO e expressões metafóricas

\begin{tabular}{|c|c|}
\hline \multicolumn{2}{|l|}{ FRAME: INIMIGO } \\
\hline SÉCULO XX: GRIPPE HESPANHOLA & SÉCULO XXI: COVID-19 \\
\hline $\begin{array}{l}\text { (12) "Medidas "contra" a grippe na Bahia São } \\
\text { Salvador, } 29 \text { (A.A.) } \text { ) }^{29 "}\end{array}$ & $\begin{array}{l}\text { (16) “[...] os países mais ricos do mundo } \\
\text { concentram seus esforços domésticos na luta } \\
\text { contra o novo coronavírus (Covid-19) [...] }]^{33 "}\end{array}$ \\
\hline $\begin{array}{l}\text { (13) "[...] a epidemia de grippe, que irrompeu em } \\
\text { varios pontos desta cidade }[. . .]]^{30 "}\end{array}$ & $\begin{array}{l}\text { (17) “[...] Anticorpos policlonais são como } \\
\text { uma coleção de várias proteínas capazes de } \\
\text { defender o organismo contra um patógeno } \\
{[\ldots]^{34 "}}\end{array}$ \\
\hline (14) “O mal fez incursão no Rio de Janeiro $[. . .]^{31 "}$ & $\begin{array}{l}\text { (18) "[...] O soro de pessoas curadas da } \\
\text { doença - que contém os anticorpos para } \\
\text { combatê-la - já é usado no tratamento em } \\
\text { alguns casos }[\ldots]]^{35 "}\end{array}$ \\
\hline $\begin{array}{l}\text { (15) "[...] deu conta }[\ldots] \text { das providencias e } \\
\text { medidas tomadas para evitar a invasão da } \\
\text { "influenza hespanhola" }[\ldots]]^{32 "}\end{array}$ & $\begin{array}{l}\text { (19) "[...] Quando entram em contato com } \\
\text { um invasor, como um vírus, por exemplo, elas } \\
\text { produzem anticorpos [...] Os monoclonais } \\
\text { são cópias de uma única proteína protetora } \\
\text { que comprovadamente pode neutralizar } o \\
\text { invasor }[\ldots . .]]^{36 "}\end{array}$ \\
\hline
\end{tabular}

Fonte: própria autora

O quadro 6 deixa patente que o inimigo responsável por fazer as vítimas, no século XX, é a grippe, é a epidemia de grippe, é a influenza hespanhola, é, enfim, o mal. Os três primeiros usos da linguagem, aqui apresentados e expostos em (12),

em:

http://memoria.bn.br/DocReader/DocReader.aspx?bib=089842_02\&pesq=grippe\%20hespanh ola\&pasta=ano\%20191\&pagfis=36878 Acesso em: 16 ago. 2020 .

http://memoria.bn.br/DocReader/DocReader.aspx?bib=089842_02\&Pesq=grippe\%20hespanh ola\&pagfis=36978 Acesso em: 16 ago. 2020.

em:http://memoria.bn.br/DocReader/DocReader.aspx?bib=089842_02\&pesq=grippe\%20hesp anhola\&pasta=ano\%20191\&pagfis=36796 Acesso em: 16 ago. 2020.

32

Disponível

em:

http://memoria.bn.br/DocReader/DocReader.aspx?bib=089842_02\&Pesq=grippe\%20hespanh ola\&pagfis=36840 Acesso em: 16 ago. 2020.

33 Disponível em: https://www.jornalcorreiodamanha.com.br/internacional/1661-covid-19tratamentos-mas-a-que-preco Acesso em: 16 ago. 2020.

${ }_{34}$ Disponível em: https://www.jornalcorreiodamanha.com.br/saude/2331-vacas-e-cavalos-setornam-fabricas-de-anticorpos-contra-a-covid-19 Acesso em: 16 ago. 2020.

${ }^{35}$ Disponível em: https://www.jornalcorreiodamanha.com.br/saude/2331-vacas-e-cavalos-setornam-fabricas-de-anticorpos-contra-a-covid-19 Acesso em: 16 ago. 2020.

${ }^{36}$ Disponível em: https://www.jornalcorreiodamanha.com.br/saude/2331-vacas-e-cavalos-setornam-fabricas-de-anticorpos-contra-a-covid-19 Acesso em: 16 ago. 2020. 
(13) e (15), se comparados ao exemplo expresso em (14), são mais específicos e perfilam a doença pandêmica em foco. Esses três primeiros casos, embora sejam usos da terminologia da medicina, apresentam graus de esquematicidade, de tal maneira que, em (12), grippe possui o conteúdo informacional mais esquemático, em comparação com epidemia de grippe, registrado em (13), e influenza hespanhola, documentado em (15). Mesmo esses dois últimos exemplos sendo mais específicos, contrastados com (12), diferenciam-se pela focalização, pois enquanto (13) coloca em foco o fato de a doença aparecer em diferentes regiões, por usar o termo epidemia de grippe, (15) focaliza, com o emprego de influenza espanhola, a informação sobre a localidade de onde se acreditava ter sido a doença importada e onde morreu um número elevado de pessoas que a contraíram. Já em (14), o inimigo é referenciado por um item léxico mais esquemático, utilizado, inclusive, a depender do enquadramento, em outros domínios, a exemplo do domínio RELIGIOSO. Essa generalização verificada na compreensão da doença em termos de mal, conceito relacionado ${ }^{37}$, é, no corpus, uma peculiaridade da metaforização da Gripe Espanhola.

Os usos demonstram que, também agora no século XXI, são empregados graus de esquematicidade, na conceptualização da pandemia de COVID-19. Recorreu-se, da mesma maneira, a conceptualizações mais generalizantes, como em (18) e em (19), embora sejam mais específicas do que a conceptualização vista no século XX, especificamente, em (14), quando o vírus foi compreendido como o mal. Em (18), o conteúdo informacional é mais geral, perfilado pelo hiperônimo doença, e, em (19), perfilado por invasor e vírus, elementos léxicos de conteúdo também mais esquemáticos, e, ainda que vírus seja mais específico do que patógeno, em (17), é mais esquemático do que novo coronavírus, em (16). No último caso, nomeadamente, em (19), o acionamento do frame INIMIGO permitiu entender o novo coronavírus como o adversário a ser neutralizado com estratégias

37 Para Kövecses (1990), trata-se de uma rede de conceitos associados a um dado conceito. 
e armas de defesa, bem como possibilitou uma mescla do vocabulário da guerra com o da saúde. Ademais, essa conceptualização mais generalizante, identificada em (19), encobre outras partes das bases que não foram perfiladas, como TENENTE, MAJOR, BRIGADEIRO, CORONEL, MARECHAL, do domíniofonte, assim como SARS-CoV-2 do domínio-alvo, que carregariam mais detalhes, portanto, maior especificidade.

Então, como no século passado e como já assinalado, agora também ocorreram graus de esquematicidade/especificidade, entre o mais geral e o mais específico. Enfim, identificou-se, no corpus, patógeno, em (17), vírus, em (19), e novo coronavírus, em (16). Enquanto patógeno, como hiperônimo, não especifica o agente da doença, se, por exemplo, é uma bactéria ou um protozoário, vírus, como hipônimo, traz mais conteúdo informacional, apresentando o inimigo como um tipo específico de patógeno, no caso, aqueles que não têm metabolismo independente e com habilidade de se replicarem, quando se introduzem nas células hospedeiras. Por fim, novo coronavírus, como hipônimo de vírus, especifica qual entre os agentes causa a doença.

Embora nos dois séculos, haja essa escala de esquematicidade/especificidade, nessas conceptualizações, a atenção foi posta em áreas diversas da base, pois, enquanto nos exemplos do século XX apenas a doença foi focalizada, nos do XXI, além da doença, a focalização também foi direcionada ao agente. Por conseguinte, ocorreram perfilamentos diversos, decorrentes de recortes conceptuais distintos feitos na mesma base conceptual.

O acionamento do frame ESTRATÉGIA DE GUERRA, por sua vez, torna possível compreender que, para ganhar a guerra contra o vírus, é necessário o planejamento coordenado de ações militares para alcançar o êxito nesse conflito bélico, de tal modo que operações de ataque e/ou de defesa devem ser planejadas e efetivadas para vencê-lo: 
Quadro 7 - Frame ESTRATÉGIA DE GUERRA e expressões

\begin{tabular}{|c|c|}
\hline FRAME: ESTRATÉGIA DE GUERRA & \\
\hline SÉCULO XX: GRIPPE HESPANHOLA & SÉCULO XXI: COVID-19 \\
\hline $\begin{array}{l}\text { (20) "[...] deu conta }[. . .] \text { das providencias e medidas } \\
\text { tomadas para evitar a invasão da "influenza } \\
\text { hespanhola" }[\ldots . .]^{38 \text { " }}\end{array}$ & $\begin{array}{l}\text { (25) "Cientistas [...] estão usando animais de } \\
\text { grande porte para produção de soro com } \\
\text { anticorpos contra o novo coronavírus }[. . .]^{43 "}\end{array}$ \\
\hline $\begin{array}{l}\text { (21) "Medidas "contra" a grippe na Bahia São } \\
\text { Salvador, } 29 \text { (A.A.) [...] }]^{39 "}\end{array}$ & $\begin{array}{l}\text { (26) "[...] quando a pessoa entrar em contato } \\
\text { com o vírus real, seu corpo já terá montado um } \\
\text { sistema de defesa contra ele } \text { el4" }^{44}\end{array}$ \\
\hline $\begin{array}{l}\text { (22) “[...] Respondo telegramma pedis noticias } \\
\text { medidas prophylaticas brasileiras contra } \\
\text { enfermidade epidemica }{ }^{40 "}\end{array}$ & $\begin{array}{l}\text { (27) "Fechar fronteiras e restringir viagens não } \\
\text { são a melhor estratégia para impedir o contágio } \\
\text { pelo novo coronavirus } 45 \text { " }\end{array}$ \\
\hline $\begin{array}{l}\text { (23) "[...] melhor execução operações sanitárias } \\
{[\ldots]^{41 "}}\end{array}$ & $\begin{array}{l}\text { (28) "As fases } 2 \text { e } 3 \text { do estudo de Oxford } \\
\text { pretendem recrutar mais de } 10 \text { mil pessoas } 46 \text { " }\end{array}$ \\
\hline $\begin{array}{l}\text { (24) "[...] evitar a permanencia em lugares fechados } \\
{[\ldots] \text { onde esteja algum atacado do resfriado mal }} \\
{[\ldots]^{42 "}}\end{array}$ & $\begin{array}{l}\text { (29) "A fragilidade dos sistemas de saúde e a } \\
\text { carência de equipamentos básicos são fatores que, } \\
\text { apesar da mobilização dos governos, trarão } \\
\text { dificuldades adicionais no enfrentamento da } \\
\text { pandemia. [...] }]^{47 "}\end{array}$ \\
\hline
\end{tabular}

Fonte: própria autora

${ }^{38}$ Disponível em:

http://memoria.bn.br/DocReader/DocReader.aspx?bib=089842_02\&Pesq=grippe\%20hespanh ola\&pagfis=36840 Acesso em: 15 ago. 2020 .

39

Disponível

em:http://memoria.bn.br/DocReader/DocReader.aspx?bib=089842_02\&pesq=grippe\%20hesp anhola\&pasta=ano\%20191\&pagfis=36878 Acesso em: 15 ago. 2020.

$40 \quad$ Disponível em:

http://memoria.bn.br/DocReader/DocReader.aspx?bib=089842_02\&Pesq=grippe\%20hespanh ola\&pagfis=36909 Acesso em: 15 ago. 2020.

41

Disponível

em:

http://memoria.bn.br/DocReader/DocReader.aspx?bib=089842_02\&Pesq=grippe\%20hespanh 3ola\&pagfis=36909 Acesso em: 15 ago. 2020.

Disponível

em:

http://memoria.bn.br/DocReader/DocReader.aspx?bib=089842_02\&pesq=grippe\%20hespanh ola\&pasta=ano\%20191\&pagfis=36796 Acesso em: 15 ago. 2020.

43 https://www.jornalcorreiodamanha.com.br/saude/2331-vacas-e-cavalos-se-tornamfabricas-de-anticorpos-contra-a-covid-19 Acesso em: 15 ago. 2020.

${ }^{44} \mathrm{https}$ //www.jornalcorreiodamanha.com.br/saude/2687-segundo-estudo-vacina-de-oxfordcontra-covid-19-e-segura-e-da-resposta-imune Acesso em: 15 ago. 2020.

${ }^{45}$ Disponível em: https://www.jornalcorreiodamanha.com.br/internacional/2762-oms-afirmaque-fechar-fronteiras-e-ineficaz-para-evitar-o-avanco-da-covid-19 Acesso em: 15 ago. 2020.

46 Disponível em: https:/www.jornalcorreiodamanha.com.br/saude/2687-segundo-estudovacina-de-oxford-contra-covid-19-e-segura-e-da-resposta-imune Acesso em: 15 ago. 2020.

${ }^{47} \mathrm{https}$ ://www.jornalcorreiodamanha.com.br/internacional/1661-covid-19-tratamentos-masa-que-preco Acesso em: 15 ago. 2020. 
Como expresso no quadro 7, no século XX, providências, em (20), medidas, em (21), ou medidas profiláticas, em (22), e operações sanitárias, em (23), são compreendidas como estratégias de defesa contra o vírus inimigo. Nesses exemplos, há maior grau de esquematicidade na conceptualização, por isso, no século passado, foi feito um uso de itens léxicos mais gerais que podem ser usados no âmbito da guerra e fora desse domínio, a exemplo de medidas, em (20) e (21), e de providência, em (20), dependendo apenas dos enquadramentos feitos pelo conceptualizador na situação interacional. $\mathrm{O}$ uso desses itens do léxico revela diferentes perspectivações, em consequência, dos distintos perfilamentos decorrentes de recortes da base conceptual mais ampla. Alguns desses itens léxicos foram inclusive adjungidos a qualificativos que os colocam, devido ao processo metafórico em pauta, no domínio SAÚDE, como medidas prophylaticas, em (22), e operações sanitárias, em (23).

Ademais, nos usos linguísticos dos Novecentos, evitar, em (20) e (24), atacado, em (24), e contra, em (21) e (22), emergem da experiência de força que se faz presente na vivência das guerras e perspectivam a aplicação das estratégias de defesa que tem a finalidade de barrar e parar o vírus aniquilador de vidas humanas, tratando-se, portanto, da Dinâmica de Forças ${ }^{48}$, uma das operações de conceptualização que aqui está sendo apenas comentada lateralmente, por não ter sido objeto do estudo cujos resultados são aduzidos neste artigo.

No tocante ao século XXI, as estratégias de guerra utilizadas contra o novo coronavírus são o fechamento de fronteiras, em (27), o recrutamento de pessoas, em (28), a montagem de um sistema de defesa, em (26), além do emprego de animais de grande porte para produção de soro, em (25). Com exceção do registro em (24), esses usos, se comparados aos coletados no século XX, a exemplo de providências $e$ medidas, em (20), demonstram maior especificidade, pois apresentam maiores

${ }^{48}$ A dinâmica de forças refere-se ao tratamento linguístico de distintas formas de força e barreiras. Trata-se, portanto, de uma categoria semântica que inclui exercício de força, resistência, superação de resistência, bloqueio de força e remoção de bloqueio (TALMY, 1988). 
detalhes informacionais. Mas se por um lado, a linguagem expressa, em (25) (usando animais de grande porte para produção de soro com anticorpos contra o novo coronavírus), uma especificidade que não foi identificada no século passado, o que pode ser explicado pelas novas experiências tecnológicas, por outro, agora no século XXI, em (29), são perfiladas a fragilidade e a falta de estratégia para o combate ao vírus, o que não foi identificado no período anterior. Nesse sentido, vale observar que apontar a fragilidade e, sobretudo, negar a existência de estratégias bem definidas para tratamento do problema sanitário não elimina a evocação do frame ESTRATÉGIA DE GUERRA nessa conceptualização.

E assim como aconteceu com os exemplos do século $X X$, agora os itens léxicos contra, em (25) e (26), restringir e impedir, em (27), perspectivam a aplicação de estratégias de defesa para o enfrentamento da pandemia, como posto em (29). Em (28), embora o recrutamento seja usado nos conflitos armados, para que soldados executem ações concomitantes de ataque e de defesa, na expressão da metaforização da pandemia em termos de guerra constante deste exemplo, o que parece ser perspectivado é a defesa, uma vez que as pessoas são convocadas para a verificação da eficácia de uma arma de defesa, isto é, da vacina.

Já o acionamento do frame ARMA possibilitou compreender, no século $\mathrm{XXI}$, a produção de soro com anticorpos, as proteínas e as vacinas em termos de recursos armamentícios, portanto em termos de mecanismos, de instrumentos, de aparelhos feitos ou mesmo adaptados para gerar vantagens nos conflitos bélicos e assim alcançar a vitória na guerra contra o novo coronavírus, como é possível verificar no quadro a seguir apresentado: 
Quadro 8 - Frame ARMA e expressões

\begin{tabular}{|c|c|}
\hline \multicolumn{2}{|l|}{ FRAME: ARMA } \\
\hline SÉCULO XX: GRIPE ESPANHOLA & SÉCULO XXI: COVID-19 \\
\hline $\begin{array}{l}\text { No corpus do século } \mathrm{XX} \text {, não foram } \\
\text { identificados exemplos do acionamento desse } \\
\text { frame. }\end{array}$ & $\begin{array}{l}\text { (30) "[...] O soro de pessoas curadas da doença - } \\
\text { que contém os anticorpos para combatê-la - já é } \\
\text { usado no tratamento em alguns casos [...] } \\
\text { Anticorpos policlonais são como uma coleção } \\
\text { de várias proteínas capazes de defender o } \\
\text { organismo contra um patógeno }[. . .]]^{49 "} \\
\text { (31) "[...] Os monoclonais são cópias de uma } \\
\text { unica proteína protetora que comprovadamente } \\
\text { pode neutralizar o invasor }[\ldots . . .]^{50 "}\end{array}$ \\
\hline & $\begin{array}{l}\text { (32) "No entanto, precisamos de mais } \\
\text { pesquisas antes de confirmar que a vacina é } \\
\text { eficaz em proteger contra o coronavírus e por } \\
\text { quanto tempo a proteção vai durar } 51 \text { " }\end{array}$ \\
\hline
\end{tabular}

Fonte: própria autora

No século XX, como já posto, não foram localizados exemplos de linguagem atrelados ao acionamento do frame ARMA, talvez, porque, no princípio da pandemia de Gripe Espanhola (o corpus foi formado a partir de publicações feitas no início da manifestação da doença no Brasil), as estratégias para seu enfrentamento ainda não tivessem sido definidas, além do estabelecimento de medidas prophylaticas e de operações sanitárias, entre outras ações mais gerais; talvez, porque a tecnologia da área de saúde não estivesse tão avançada para apontar, como hoje, logo no começo do problema sanitário, o caminho para a vacinação, ou, talvez, simplesmente, porque o corpus não tenha conseguido capturar esse frame antes de a coleta ter sido concluída pela saturação do domínio-fonte.

A linguagem utilizada, no século XXI, é oriunda da área de saúde e evidencia uma perspectivação com alto grau de especificidade, como demonstra

${ }^{49}$ Disponível em: https://www.jornalcorreiodamanha.com.br/saude/2331-vacas-e-cavalos-setornam-fabricas-de-anticorpos-contra-a-covid-19 Acesso em: 15 ago. 2020.

${ }^{50}$ Disponível em: https://www.jornalcorreiodamanha.com.br/saude/2331-vacas-e-cavalos-setornam-fabricas-de-anticorpos-contra-a-covid-19 Acesso em: 15 ago. 2020.

51 Disponível em: https://www.jornalcorreiodamanha.com.br/saude/2687-segundo-estudovacina-de-oxford-contra-covid-19-e-segura-e-da-resposta-imune Acesso em: 15 ago. 2020. 
o uso das expressões linguísticas empregadas: anticorpos policlonais, proteína, em (30), monoclonal, em (31), ou até mesmo vacina, em (32). Nesse sentido, cabe ressaltar que a metáfora da guerra possibilita a compreensão de soluções, de substâncias etc., usadas no âmbito da medicina, em termos de armas, tornando assim o que é desconhecido em algo compreensível.

Então, com essa conceptualização metafórica, é possível escrever sobre uma área técnica, árida para a maioria da população, usando a experiência bélica que, embora não seja prototipicamente vivida no país, acompanha a humanidade em toda sua existência, de tal forma que, mesmo sem ter vivido uma guerra, aqueles que a conhecem, desde sua infância, por meio de brincadeiras ou de desenhos animados, e, ao longo de toda sua vida, através de livros de história, documentários, reportagens, filmes, poemas, prosas, entre outros registros de modelos culturais, poderá compreender a experiência de tratamento da doença em seus termos, com a utilização de armas de defesa, entre outras estratégias, para derrotar o inimigo, isto porque conseguirá acionar parte do conhecimento armazenado na memória social, nos modelos cognitivos idealizados construídos sobre as vivências do guerrear no devir da história e, com isso, poderá comparálo com uma área específica da vida humana, explorada por algumas poucas pessoas, mas que precisa ser melhor e rapidamente compreendida por todos no planeta, quando todos se debatem com graves problemas sanitários, quer isto tenha ocorrido no passado, quer esteja acontecendo no tempo presente.

Para a conceptualização metafórica dessas doenças pandêmicas em termos de GUERRA, o frame VITÓRIA também foi requerido. Este acionamento possibilitou entender que é possível triunfar sobre um inimigo vírus, usando estratégias, como as operações sanitárias e o fechamento de fronteiras, empregando armas, como as vacinas, a partir de um planejamento elaborado por generais, como os diretores da saúde e os cientistas, posto efetivamente em prática por soldados, como os voluntários profissionais da saúde, em combates e lutas que ocorrem em um campo de batalha, na sua linha de frente, para que assim o 
insucesso militar diante do perigoso oponente seja evitado, para que a superioridade humana possa impeli-lo à derrota e, desta maneira, os humanos possam alcançar o triunfo da guerra, isto é, a liberdade de respirar sem medo:

Quadro 9 - Frame VITÓRIA e expressões metafóricas

\begin{tabular}{|c|c|}
\hline SÉCULO XX: GRIPPE HESPANHOLA & SÉCULO XXI: COVID-19 \\
\hline $\begin{array}{l}\text { (33) "Tendo o dr. Seidi informado ao ministro } \\
\text { das providencias que têm sido tomadas para } \\
\text { debellar a epidemia de grippe, que irrompeu em }\end{array}$ & $\begin{array}{l}\text { No corpus do século } \mathrm{XXI} \text {, não foram } \\
\text { identificados exemplos do acionamento } \\
\text { desse frame. }\end{array}$ \\
\hline
\end{tabular}
varios pontos desta cidade $[. . .]^{52 "}$

Fonte: própria autora

Apesar da possibilidade de acionamento do frame VITÓRIA para a conceptualização metafórica em pauta, apenas no corpus do século XX, foi localizado um uso linguageiro, especificamente, em (33), que expressa a ativação do referido frame para compreender a Gripe Espanhola em termos de GUERRA. Trata-se de uma conceptualização mais esquemática, considerando que debelar perfila a possibilidade de impor a vitória por meio de luta armada contra o novo coronavírus, sem maiores especificações de como será esse triunfo.

Em face dessa ausência de expressões linguísticas no corpus do século XXI que manifestassem o mapeamento desse frame do domínio GUERRA para o da DOENÇA, ponderou-se que essa ausência poderia se dever exclusivamente ao fato de a amostra destacada não trazer essa perspectivação. Para testar essa hipótese, procedeu-se à procura pela expressão linguística debelar o coronavírus/COVID-19, na internet, usando, para tal, o motor de busca do Google. Com isto, foram localizados alguns usos, como os que são apresentados a seguir: Dia 14 de maio: o mundo em oração para debelar o coronavírus53; Caiado volta a pedir a colaboração de todos para debelar o Coronavírus ${ }^{54}$ e Seis meses depois, a DWfaz um

http://memoria.bn.br/DocReader/DocReader.aspx?bib=089842_02\&Pesq=grippe\%20hespanh ola\&pagfis=36978 Acesso em: 15 ago. 2020.

53 Disponível em: http://www.ihu.unisinos.br/78-noticias/598897-dia-14-de-maio-o-mundoem-oracao-para-debelar-o-coronavirus Acesso em: 19 ago. 2020.

${ }^{54}$ Disponível em: Caiado volta a pedir a colaboração de todos para debelar o Coronavírus ABC Acesso em: 19 ago. 2020. 
levantamento sobre a evolução do vírus Sars-Cov-2 em pandemia e os esforços para debelar a covid-1955". Desta maneira, constatou-se que, de fato, se tratava de um vazio deixado pelo corpus e concluiu-se que, também no século XXI, ocorreu a focalização da vitória sobre o vírus e a doença, embora não tenham sido localizados exemplos na amostra estudada.

Apresentado o estudo do corpus, a seguir, aduzem-se as considerações finais.

\section{PARA CONCLUIR A DISCUSSÃO}

No corpus, o domínio-fonte GUERRA participa da conceptualização de DOENÇA, por meio dos frames: 1) AÇÃO BÉLICA, 2) ESTRATÉGIA DE GUERRA, 3) GENERAL, 4) SOLDADO, 5) SOLDADO MORTO, 6) INIMIGO, 7) ARMA, 8) CAMPO DE BATALHA e 9) VITÓRIA, logo a metáfora DOENÇA É GUERRA concentra-se em pelo menos nove perfis distintos. Todavia, no contexto das pandemias de Gripe Espanhola e de COVID-19, mais especificamente, no corpus, apenas os seis primeiros frames foram demandados nos dois períodos. No material textual estudado, o antepenúltimo e o penúltimo só foram requeridos no século XXI, enquanto o último frame só foi acionado no século XX.

Como assinalado na seção teórica deste artigo, a variação do significado é decorrente da própria natureza da conceptualização, resultando da perspectivação conceptual, por conseguinte, há sempre, como demonstrou o estudo do corpus, diferentes formas de dizer algo sobre essas pandemias. Enfim, os significados dessas doenças apresentam variação, devido à própria capacidade humana de conceptualizar, logo, de falar, de escrever e também de agir a partir de perspectivas alternativas.

As formas diferentes de dizer e de escrever, considerando o recorte feito para o tratamento do corpus, são decorrentes da diferenciação de graus de

55 Disponível em: Após seis meses, o que se sabe sobre a covid-19? - CartaCapital Acesso em: 19 ago. 2020. 
esquematicidade/especificidade, de tal sorte que são feitos usos de hiperônimos e de hipônimos, bem como de construções mais gerais e específicas que perfilam distintas partes da base conceptual acionada para conceptualizar essas doenças pandêmicas, e isto se deve a diferenças acerca do direcionamento da atenção dos conceptualizadores, quando se colocaram a conceptualizar cada uma dessas duas pandemias, em suas respectivas épocas, além de diferenças sociais decorrentes dos avanços tecnológicos no âmbito da ciência, no tempo presente que acabam por interferir no modo de significar a COVID-19.

Ademais, como já esperado, foi posto em evidência que o resultado do estudo do corpus não expressa a completude dos usos semânticos de um dado momento da história, devido à limitação do corpus. Mas mesmo que não seja possível abarcar em um estudo semântico cognitivo sócio-histórico toda a abrangência da significação, as reflexões aqui apresentadas colaboram para o entendimento de como ocorre o funcionamento da conceptualização na flecha do tempo. E em face das lacunas inerentes ao estudo semântico da linguagem do passado e também do presente, cabe a realização de outras pesquisas, a fim de melhor compreender como o significado é gerado, como funciona na linguagem e como atua na construção das realidades e das ações humanas ontem e hoje.

\section{REFERÊNCIAS}

ALBERGARIA, G.; MIRANDA, N. S. Mudança semântica e expansão categorial no léxico do PB: o caso de um frame 'animal'. 2011. Disponível em: https://www.ufff.br/revistaveredas/files/2011/05/artigo-102.pdf Acesso em: 01 de ago. de 2020.

ALMEIDA, A. A. D. A semântica sócio-histórico-cognitiva: antecedentes, estado da arte e propostas para o futuro. In: SANTANA, N.; ALMEIDA, A. A. D. Semântica CognitivaSócio-Histórica: estudos sobre o significado. Salvador: EDUNEB, 2020a, p. 23-61.

ALMEIDA, A. A. D. A tessitura do conhecimento: o corpus na construção de estudos semânticos sócio-histórico-cognitivos. In: SOUZA, R.; BORGES, R.; Almeida, I.; SOUZA, D. Filologia me diálogo: descentramentos culturais e epistemológicos. Salvador: Arte \& Memória, 2020b, p. 148-184. 
ALMEIDA, A. A. D.; SANTOS, E. S. dos. Ciência, opinião e Fake News em tempos de coronavírus: conceptualizações em memes sob a abordagem da linguística cognitiva. 2020. Disponível em: CIÊNCIA, OPINIÃO E FAKE NEWS EM TEMPOS DE CORONAVÍRUS: CONCEPTUALIZAÇÕES EM MEMES SOB A ABORDAGEM DA LINGUÍSTICA COGNITIVA / Science, opinion and fake news in times of the coronavirus: conceptualizations in memes under Cognitive Linguistics approach I Domingues Almeida I Pensares em Revista (uerj.br) Acesso em 15 de ago. de 2020.

BARCELONA, A (Eds). Metaphor and Metonymy at the Crossroads: A Cognitive Perspective. Berlin/New York: Mouton de Gruyter, 2003.

CROFT, W.; CRUSE, D. A. Lingüística cognitiva. Tradução por Antonio Benítez Burraco. Madrid: Akal, 2008.

FERNÁNDEZ JAÉN, J. Breve historia de la semántica histórica. Interlingüística, Valencia, n. 17, p. 345-354, 2007. Disponível em: https://bit.ly/38q3ODo. Acesso em: 25 jul. 2016.

FERNÁNDEZ JAÉN, J. Semántica histórica: introducción y contextualización. Anuari de Filologia, Estudios de Lingüística, Barcelona, n. 6, p.55-61, 2016. Disponível em: https://bit.ly/31P4iSo. Acesso em: 30 jan. 2019.

FILLMORE, C. J. Semântica de Frames. Tradução por Galeno Fae da Silva. Cadernos de Tradução. Porto Alegre, n. 25, p. 25-53, jul-dez de 2009 [1982].

GEERAERTS, D. Diachronic Prototype Semantics: A Contribution to Historical Lexicology, Oxford, Clarendon Press, 1997.

KÖVECSES, Z. Levels of metaphor. Cognitive Linguistics, Berlin, v. 2, n. 28, p. 321-347, 2017.

KÖVECSES, Z. Emotion concepts. New York: Springer-Verlag, 1990.

LAKOFF, G. Women, Fire, and Dangerous Things. What Categories Reveal about the Mind. Chicago: The University of Chicago Press, 1987.

LAKOFF, G.; JOHNSON, M. Metaphors we live by. Chicago: Chicago Press, 1980.

LAKOFF, G.; JOHNSON, M. Metáforas da vida cotidiana. Coordenação de tradução Mara Sophia Zanotto. Campinas-SP: Mercado de Letras; São Paulo: EDUC, 2002 [1980].

LAKOFF, G. Política moral. Cómo piensan progresistas y conservadores. Tradução por Miguel Marqués. Madird: Capitán Swing, 2016 [1996].

LAKOFF, G. Puntos de reflexión: Manual del progresista. Tradução por Judith Wells. Barcelona: Península, 2013 [2006].

MATTOS E SILVA, R. V. Caminhos da Linguística Histórica: "ouvir o inaudível". São Paulo: Parábola Editorial, 2008. 
PAZ AFONSO, A. Semántica Cognitiva e historia del léxico: evolución de los verbos entrar y salir (ss. XIII-XIV). 2014. 531 f. Tese (Doutorado em Filologia Espanhola) Universitat Autònoma de Barcelona, Bellaterra. Disponível em: https://bit.ly/3fLXTuy. Acesso em: 4 ago. 2020.

SALOMÃO, M; TORRENT, T.; SAMPAIO, T. A linguística cognitiva encontra a linguística computacional: notícias do projeto framenet Brasil. 2013. Disponível em: https://www.periodicos.sbu.unicamp.br/ojs/index.php/cel/article/view/8636592/4311.

Acesso em: 01. de ago. de 2020.

SANTANA, N. M. O. Estudo sócio-histórico-cognitivo das conceptualizações e categorizações do amor em cartas dos séculos XIX e XX. 210 f. Tese (Doutorado em Língua e Cultura), Instituto de Letras - Universidade Federal da Bahia, UFBA, Salvador.

SILVA, A. S. da. Gramática, cognição e sociedade: para uma gramática de significados, usos e variações. 2019. Disponível em (PDF) Gramática, cognição e sociedade: para uma gramática de significados, usos e variações (researchgate.net) Acesso em: 01. de ago. de 2020.

SILVA, A. S. da. Perspectivação conceptual e gramática. 2008. Disponível em: 2008_Perspetivacao_conceptual_gramatica (1).pdf Acesso em: 15 de ago. de 2020.

SILVA, A. S. da.; BATORÉO, H. J. Gramática Cognitiva: estruturação conceptual, arquitectura e aplicações. 2016. Disponível em: 16-Augusto Soares.indd (up.pt) Acesso em: 15 de ago. de 2020.

SOUSA, M. C. P. de. Lingüística histórica. 2006. Disponível em: https://bit.ly/2DxT5Mw. Acesso em: 4 ago. 2020.

TALMY, L. Force dynamics in language and cognition. In: EILFORT, W; KROEBER, P; PETERSON, K. Papers from the parasession on causatives and agentivity at the 21 st regional meeting. Chicago: University de Chicago, 1988.

Nota do editor:

Artigo submetido para avaliação em: 15 de novembro de 2020.

Aprovado em sistema duplo cego em: 20 de fevereiro de 2021. 